\title{
Experimental Investigation of Changing Polarity in Powder Mixed Electric Discharge Machining (PM-EDM)
}

\author{
Mr. Pankaj B. Gavali*, Mr. Chandan A.Waghmare** and Dr. S. S. Kalashetty*** \\ *Assistant Professor Sanjay Ghodawat Institute, Atigre, Kolhapur, 416118. \\ ** Assistant Professor Rajarambapu Institute of Technology, Rajaramnagar, Islampur 415409. \\ *** Head and Associate Professor Industrial \& Production Engineering Department, \\ PDA College of Engineering, Kalaburgi, 585102. \\ *gavali.pb@sginstitute.in \\ **chandan_w@rediffmail.com \\ ***sonu1196@rediffmail.com
}

\begin{abstract}
It is the common practice in EDM to make tool positive and work piece negative (Normal polarity), but researches shows that reverse of it is also possible in which tool is negative and work piece is positive ( Reverse polarity). Paper discusses the effect of polarity on the machining characteristics with chromium powder suspended dielectric in electric discharge machining. High metal removal rate, low tool wear rate and surface roughness are conflicting goals, which cannot be achieved simultaneously with a particular combination of control settings. To achieve the best machining results, the goal has to betaken separately in different phases of work with different emphasis. A L9 orthogonal array is designed for both polarities. Copper is used as tool material and EN-19 alloy steel is selected as work piece material with normal and reverse polarities.
\end{abstract}

The study reveals that Normal polarity is suitable for higher metal removal rate and lower tool wear but reverse polarity gives minimum surface roughness as compared to normal polarity. Normal polarity gives 10-21 times more MRR and 4 times less tool wear rate as compared to reverse polarity, and reverse polarity gives 1.5-2 times better surface finish as compared to Normal polarity.

Keywords: - Polarity, PMEDM, MRR, TWR, EDM.

\section{INTRODUCTION}

In 1770, the English scientist, Priestley, first detected the erosive effect of electrical discharges on metals. During research (to eliminate erosive effects on electrical contacts) the soviet scientists, Lazarenko and Lazarenko (1940), decided to exploit the destructive effect of an electrical discharge and developed a controlled method of metal machining. In 1943, they announced the construction of the first Spark Erosion machine. The spark generator used in 1943, known as the Lazarenko circuit, has been employed over many years in powder supplies for EDM machines and an improved version is being used in many current applications.

Electrical discharge machining (EDM) is non-traditional manufacturing process where material is removed by a succession of electrical discharges. Pulsed arc discharges occur in the gap filled with an insulating medium between tool electrode and work piece. Its unique feature of using thermal energy to machine electrically conductive parts regardless of hardness has been its distinctive advantage. However, it suffers from few limitations such as low machining efficiency and poor surface finish. To overcome these limitations the electrically conductive powder particles are mixed in the dielectric fluid, which reduces its insulating strength and increases the spark gap distance between the tool and workpiece. This new hybrid material removal process is called Powder mixed EDM (PM-EDM) Figure 1. In PM-EDM a suitable metal powder is mixed into the dielectric used in EDM.The additive particles suspended in the dielectric has important influence on the discharge process; increase both the gap distance \& the discharging rate. The high electric field energises the conductive powder particles. These conductive particles form chains at different places under sparking area, which bridges the gap between tool electrode \& work piece material. Due to this bridging effect, the gap voltage $\&$ insulting strength of the dielectric decreases, this causes easy short circuiting and hence early explosion in the gap between the electrode and the work piece. At the same time the suspended particles in the dielectric enlarged the plasma channel, because of which electric density decreases and hence uniform distribution of the sparking takes place.

B. B. Pradhan et al.presented the changing polarity for microelectric discharge machining (micro-EDM) in a systematically designed time domain while machining titanium alloy (Ti-6Al-4V) for the fabrication of straight-through microholes. Experimental investigations were made to study precisely the effects of changing polarity in micromachining of $\mathrm{Ti}-6 \mathrm{Al}-4 \mathrm{~V}$. 
S.S.Chatha et al. presented the work with an objective to modify the surface characteristics like surface roughness, material removal rate, and hardness by adding different concentrations of $\mathrm{TiO} 2$ into the dielectric fluid of EDM. X-Ray Diffraction (XRD) and MAPING analysis has been carried out to find the migration of powder from the dielectric to the machined surface. SEM of the surface and the cross-section was also done to analyze the surface texture and recast layer. The results achieved showed that minor amount of powder was migrated to machined surface, which resulted in surface improvement. The dielectric with added powder also shows significant improvement in material removal rate.

Wei Zhao et al. studied the problem of polarity effect in EDM. In order to find out the deterioration of the anode and the cathode, the experiment with single pulse was taken in kerosene oil. They found the deterioration of the anode was larger than that of the cathode even in the condition of large pulse width. But this result was contradictory with that gotten in electric discharge machining with continue pulses.

Naveen Beri et al. studied the effect of graphite powder on the machining performance of conventional EDM. The machining performance was evaluated in terms of tool wear rate. Concentration of graphite powder, polarity, electrode type, peak current, pulse on time, duty cycle gap voltage and retract distance was taken as the input parameters and their effect were presented on machining performance.

M. S. Reza et al studied the effect of polarity on the material removal rate (MRR), electrode wear ratio (EWR) and surface roughness (SR) of the tool steel work piece machining using EDM. Wrong polarity can have significant implications on speed, wear, and stability and to investigate this phenomenon using L18 orthogonal arrays design of experiment. They concluded that the positive polarity (tool -, workpiece + ) is found optimum for the all analysis on the Material Removal Rate (MRR), Electrode Wear Ratio (EWR) and Surface Roughness (SR)

Kuldeep Ojha et al. studied the parametric optimization for material removal rate (MRR) and tool wear rate (TWR) on the powder mixed electrical discharge machining (PMEDM) of EN-8 steel has been carried out. Response surface methodology (RSM) has been used to plan and analyze the experiments.

PMEDM performance in terms of MRR and TWR. Experiments have been performed on newly designed experimental setup developed in laboratory. Most important parameters affecting selected performance measures have been identified and effects of their variations have been observed.

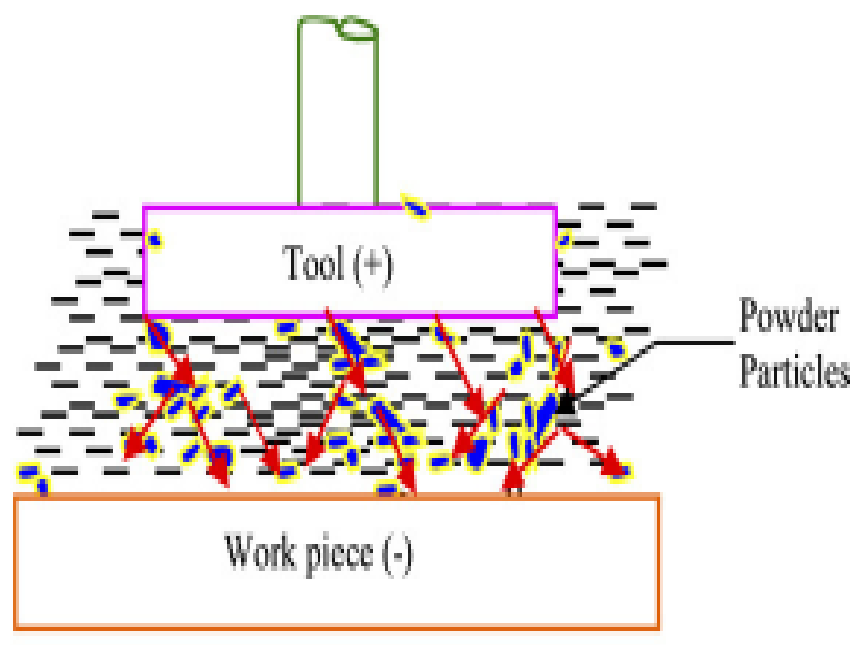

Figure1: Powder mixed EDM (PM-EDM)

A large number of input process parameters can be varied in the PMEDM process, eachhaving its own impact on output parameters such as Material Removal Rate (MRR), ToolWear Rate (TWR), and hardness of machined surface, surface finish, dimensionalaccuracy and overall surface integrity. Various input parameters are:
1. Discharge Voltage
2. Peak Current
3. Pulse Waveform
4. Pulse on-time
5. Pulse off-time
6. Pulse Frequency
7. Polarity
8. Electrode Gap 


\section{Concentration of powder}

It is known from the research works that out of the above listed parameters, four parameters directly affect the MRR, TWR and surface roughness in PMEDM. These four parameters are peak current, pulse on-time, concentration of powder and polarity. These parameters have been investigated thoroughly in this paper.

\section{EXPerimental Design}

In the present paper, an effort has been made to study the effect of powder suspended in the dielectric fluid of EDM on process performance on MRR, TWR, and Surface roughness, the design variables can besummarized as follows:

- Chromium powderis to be suspended in the dielectric fluid in three levels. Specification of Chromium powder used shown in table 3.

- Three levels of peak current to be used; because the non-linear behavior of process parameters can only be studied if more than two levels of a parameter are used.

- Experimentation is carried out in Kerosene oil. Specification of Kerosene oil is shown in table 2.

- Three levels of pulse on-time to be used.

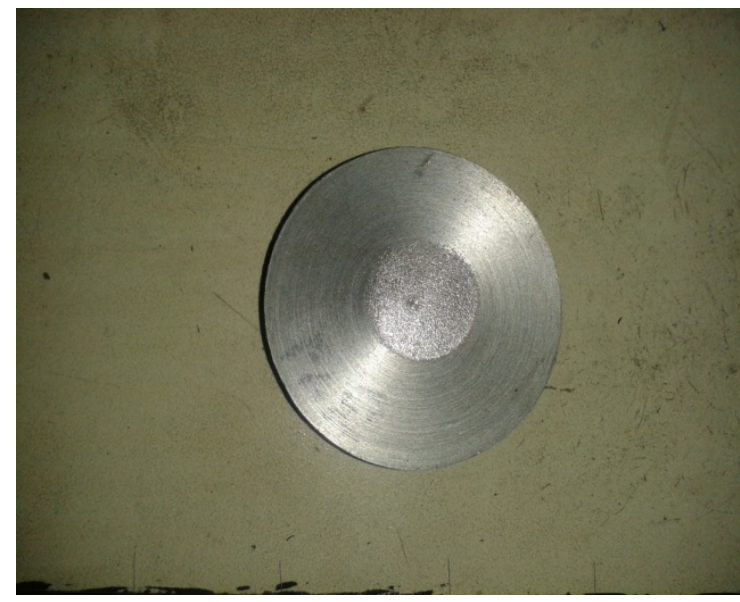

Figure 2: EN-19 alloy steel Workpiece

And the whole experimentation is to be done in L9orthogonal array with positive (straight) polarity and Negative polarity (Reverse Polarity) shown in table 6. And find out the optimum parametric combination for powder mixed EDM.

The effect of the variation ininput process parameter will be studied on these three response parameters and theexperimental data will be analyzed as per Taguchi method to find out the optimummachining condition. The machining parameters that have been kept fixed throughout the experimentation shown in table1.

Table 1: Fixed Input Process Parameters

\begin{tabular}{|l|l|l|}
\hline Sr. No. & \multicolumn{1}{|c|}{ Machining Parameter } & \multicolumn{1}{|c|}{ Fixed Value } \\
\hline 1 & Type of Dielectric & Kerosene \\
\hline 2 & Voltage(vg) & $70 \mathrm{~V}$ \\
\hline 3 & Machining time & 20 min. \\
\hline 4 & Duty Cycle $(\mathrm{t})$ & 9 \\
\hline 5 & Flushing & Straight \\
\hline 6 & SEN & 10 \\
\hline 7 & TW & 0.5 \\
\hline 8 & Rd & 0.5 \\
\hline
\end{tabular}

Table 2: Specification of Kerosene oil used

\begin{tabular}{|l|l|l|l|}
\hline $\begin{array}{l}\text { Dielectric } \\
\text { Constant }\end{array}$ & $\begin{array}{l}\text { Electric } \\
\text { Conductivity }\end{array}$ & Density & $\begin{array}{l}\text { Dynamic } \\
\text { Viscosity }\end{array}$ \\
\hline 1.8 & $1.6 * 10-4 \mathrm{~s} / \mathrm{m}$ & 730 & $0.94 \mathrm{~m}$ \\
\hline
\end{tabular}


Table 3: Specification of Chromium powder used

\begin{tabular}{|l|l|l|l|l|l|l|}
\hline $\mathrm{Cr} \%$ & $\mathrm{C} \%$ & $\mathrm{~S} \%$ & $\mathrm{P} \%$ & $\mathrm{Si} \%$ & $\mathrm{Al} \%$ & $\mathrm{Fe} \%$ \\
\hline 99 & 0.01 & 0.015 & 0.015 & 0.090 & 0.08 & 0.01 \\
\hline
\end{tabular}

Sieve Analysis: - 325

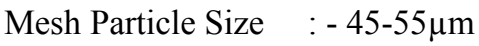

Machining was performed using copper electrode of $25 \mathrm{~mm}$ diameter having properties as shown in Table 4 and figure 3.

Table 4: Chemical Composition and mechanical properties of EN-19 alloy steel.

\begin{tabular}{|l|l|l|l|}
\hline Density & $\begin{array}{l}\text { Electrical } \\
\text { resistivity }\end{array}$ & Purity & Melting point \\
\hline $8.9 \mathrm{~kg} / \mathrm{m}^{3}$ & $0.0167 \Omega \mathrm{m} \mathrm{m}^{2} / \mathrm{m}$ & $99.8 \%$ & $10830 \mathrm{C}$ \\
\hline
\end{tabular}

Table 5: Properties of Copper electrode

\begin{tabular}{|c|c|c|c|c|c|c|c|c|c|c|c|}
\hline \multicolumn{12}{|c|}{ Chemical composition } \\
\hline $\mathrm{Fe}$ & $\mathrm{C}$ & $\mathrm{Si}$ & $\mathrm{Mn}$ & $\mathrm{P}$ & $\mathrm{S}$ & $\mathrm{Cr}$ & Mo & $\mathrm{Ni}$ & $\mathrm{Al}$ & Co & $\mathrm{Cu}$ \\
\hline 96.8 & 0.41 & 0.26 & 0.79 & 0.02 & 0.026 & 1.01 & 0.162 & 0.144 & 0.07 & 0.004 & 0.19 \\
\hline \multicolumn{12}{|c|}{ Mechanical properties of EN-19 alloy steel. } \\
\hline \multicolumn{4}{|c|}{ Tensile strength } & \multicolumn{8}{|c|}{$1150 \mathrm{~N} / \mathrm{mm} 2$} \\
\hline \multicolumn{4}{|c|}{ Yield stress } & \multicolumn{8}{|c|}{$850 \mathrm{~N} / \mathrm{mm} 2$} \\
\hline \multicolumn{4}{|c|}{ Elongation } & \multicolumn{8}{|c|}{$14-17 \%$} \\
\hline \multicolumn{4}{|c|}{ Modulus of elasticity } & \multicolumn{8}{|c|}{$210000 \mathrm{~N} / \mathrm{mm} 2$} \\
\hline \multicolumn{4}{|c|}{ Density } & \multicolumn{8}{|c|}{$7.8 \mathrm{Kg} / \mathrm{m} 3$} \\
\hline \multicolumn{4}{|c|}{ Hardness } & \multicolumn{8}{|c|}{$55 \mathrm{HRC}$} \\
\hline
\end{tabular}

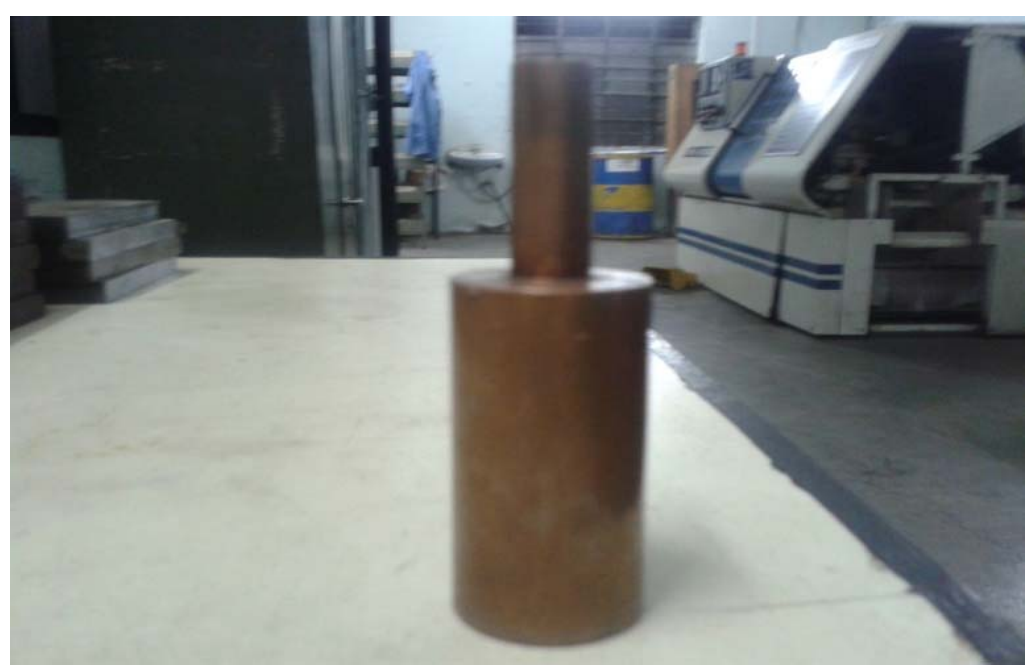

Figure 3: Copper Tool 
Table 6: Experimental plan, output responses and $\mathrm{S} / \mathrm{N}$ ratio values

\begin{tabular}{|c|c|c|c|c|c|c|c|c|c|c|}
\hline $\begin{array}{l}\text { Sr. } \\
\text { No. }\end{array}$ & Polarity & Ip & Ton & C & $\begin{array}{c}\text { MRR } \\
\text { (mm3/min) }\end{array}$ & $\begin{array}{c}\text { SNR for } \\
\text { MRR }\end{array}$ & $\begin{array}{c}\text { TWR } \\
(\mathrm{mm} 3 / \mathrm{min})\end{array}$ & $\begin{array}{l}\text { SNR for } \\
\text { TWR }\end{array}$ & $\begin{array}{l}\text { Surface } \\
\text { Roughness } \\
\text { (Ra) }\end{array}$ & $\begin{array}{l}\text { SNR for } \\
\text { SR }\end{array}$ \\
\hline 1 & + & 6 & 100 & 0 & 2.500 & 7.9588 & 0.056 & 25.0474 & 5.845 & -15.335 \\
\hline 2 & + & 6 & 200 & 1 & 2.365 & 7.4766 & 0.078 & 22.1248 & 5.664 & -15.062 \\
\hline 3 & + & 6 & 300 & 2 & 3.532 & 10.9604 & 0.073 & 22.7685 & 4.818 & -13.657 \\
\hline 4 & + & 12 & 100 & 1 & 7.458 & 17.4524 & 0.185 & 14.6771 & 7.548 & -17.556 \\
\hline 5 & + & 12 & 200 & 2 & 7.975 & 18.0346 & 0.112 & 19.0268 & 6.545 & -16.318 \\
\hline 6 & + & 12 & 300 & 0 & 6.320 & 16.0143 & 0.173 & 15.2201 & 10.862 & -20.718 \\
\hline 7 & + & 18 & 100 & 2 & 12.452 & 21.9048 & 0.459 & 6.7711 & 7.689 & -17.717 \\
\hline 8 & + & 18 & 200 & 0 & 10.371 & 20.3164 & 0.106 & 19.4723 & 11.105 & -20.910 \\
\hline 9 & + & 18 & 300 & 1 & 11.474 & 21.1943 & 0.095 & 20.4384 & 9.857 & -19.874 \\
\hline 10 & - & 6 & 100 & 0 & 0.186 & -14.6097 & 0.084 & 21.5255 & 3.155 & -9.9800 \\
\hline 11 & - & 6 & 200 & 1 & 0.295 & -10.6036 & 0.185 & 14.6771 & 1.655 & -4.3760 \\
\hline 12 & - & 6 & 300 & 2 & 0.289 & -10.7820 & 0.157 & 16.1042 & 2.077 & -6.3487 \\
\hline 13 & - & 12 & 100 & 1 & 0.395 & -8.0681 & 0.190 & 14.4249 & 4.734 & -13.5046 \\
\hline 14 & - & 12 & 200 & 2 & 0.315 & -10.0338 & 0.151 & 16.4201 & 3.746 & -11.4714 \\
\hline 15 & - & 12 & 300 & 0 & 0.389 & -8.2003 & 0.180 & 14.8945 & 5.170 & -14.2698 \\
\hline 16 & - & 18 & 100 & 2 & 0.340 & -9.3704 & 0.278 & 11.1191 & 6.677 & -16.4916 \\
\hline 17 & - & 18 & 200 & 0 & 0.383 & -8.3439 & 0.150 & 16.4782 & 7.650 & -17.6732 \\
\hline 18 & - & 18 & 300 & 1 & 0.450 & -6.9357 & 0.134 & 17.4431 & 6.881 & -16.7530 \\
\hline
\end{tabular}

I: - Current, Ton: - Cycle on Time C: - Concentration of Powder 
III. RESULt ANALYSIS

Effect of parameters on process performance in Normal Polarity

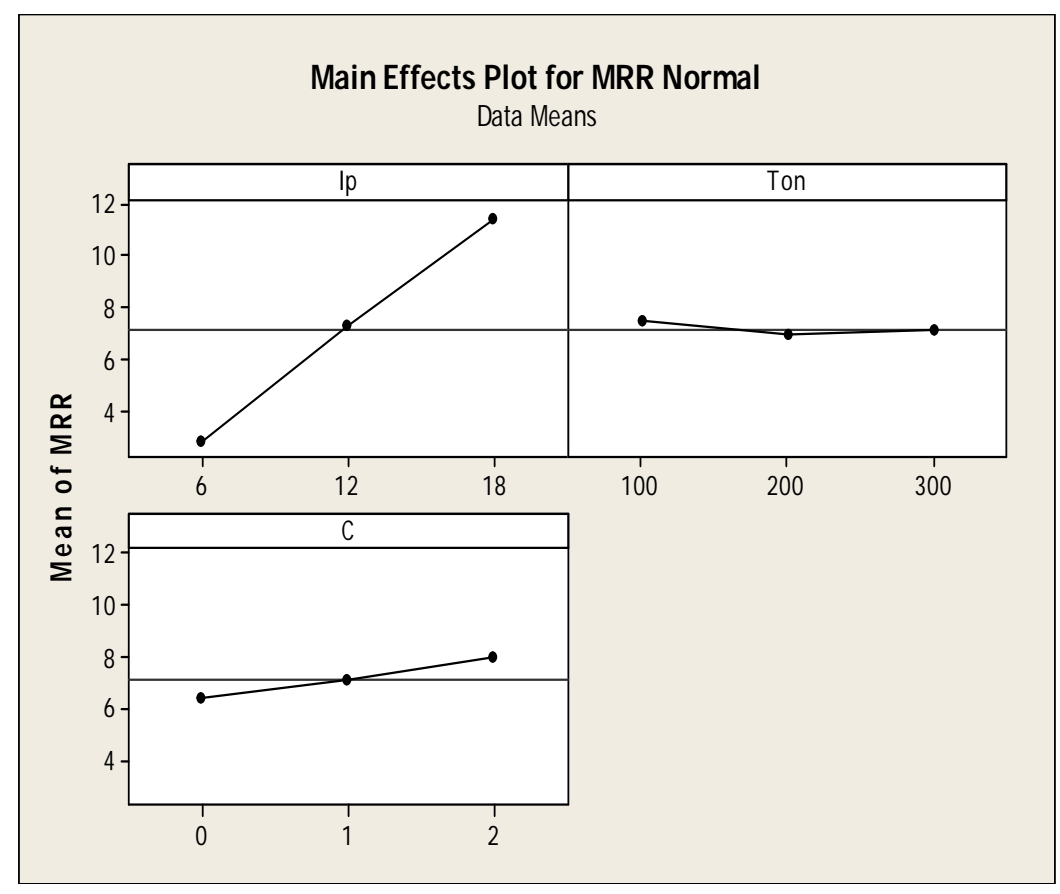

Figure: 4 Response Graph for MRR

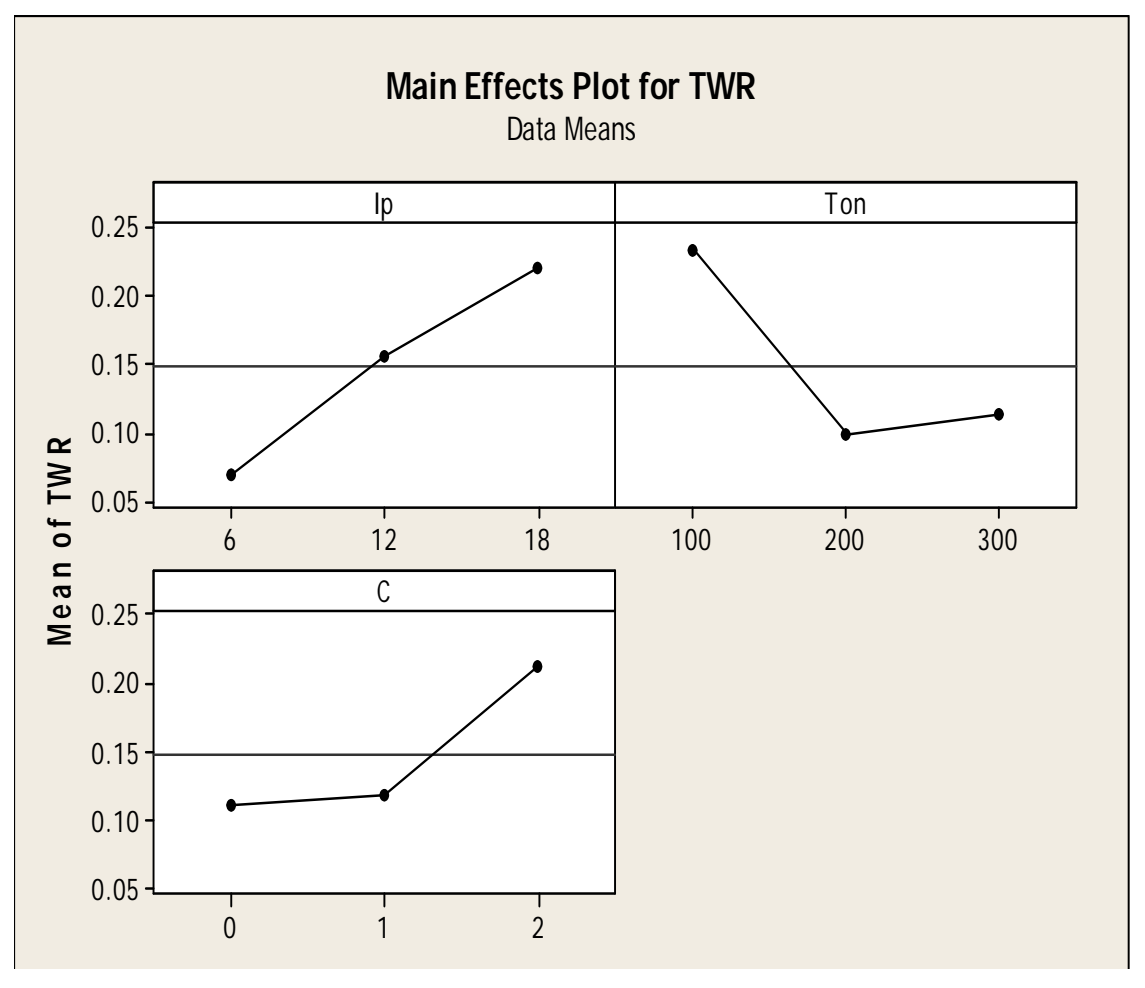

Figure:5 Response Graph for TWR 


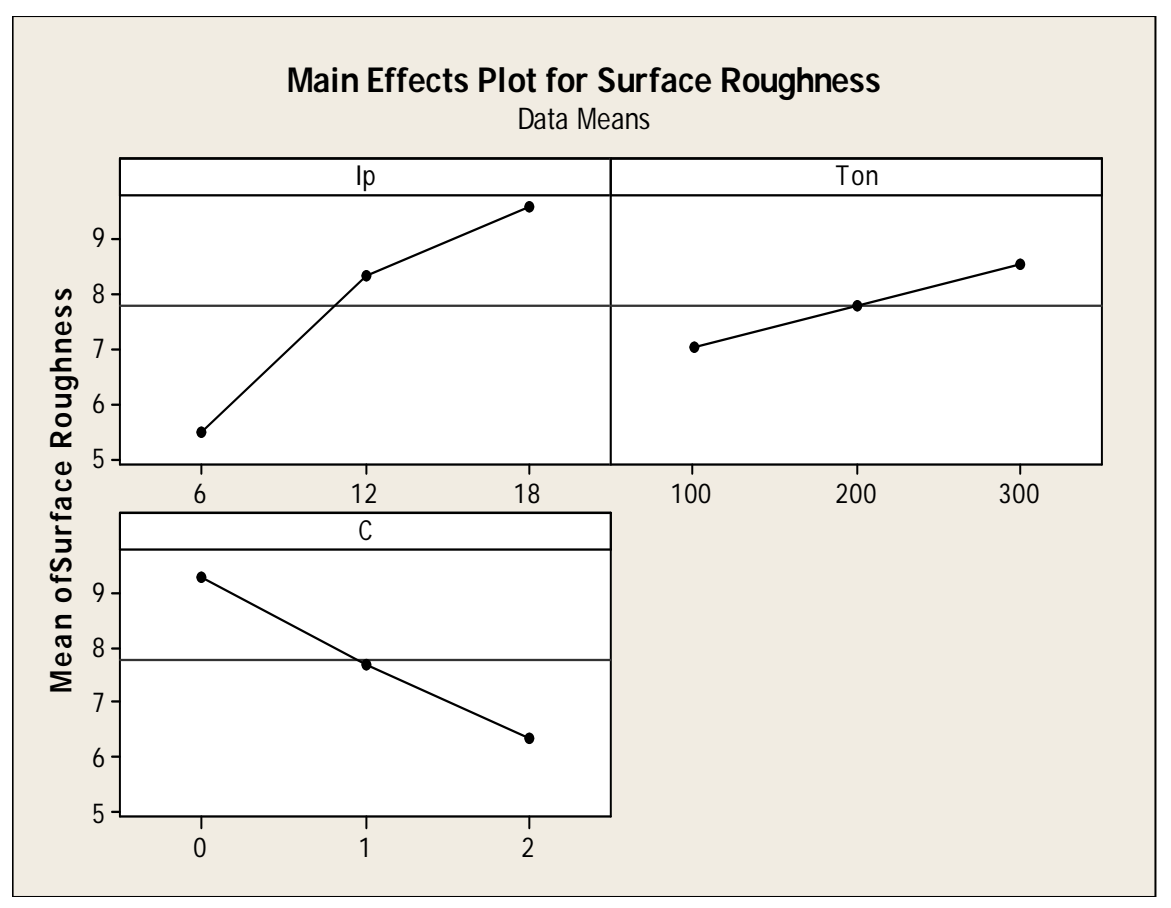

Figure: 6 Response Graph for Surface Roughness

Effect of parameters on process performance in Reverse Polarity

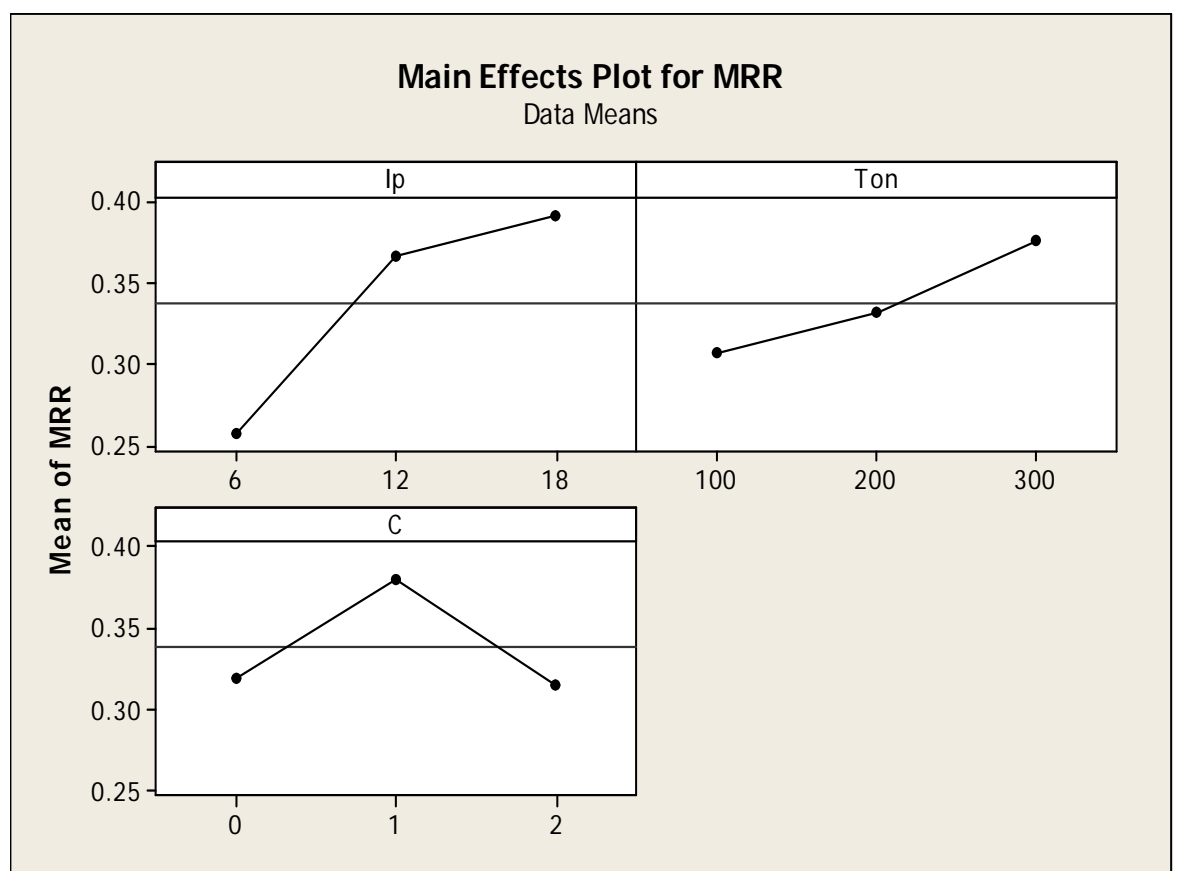

Figure: 7 Response Graph for MRR 


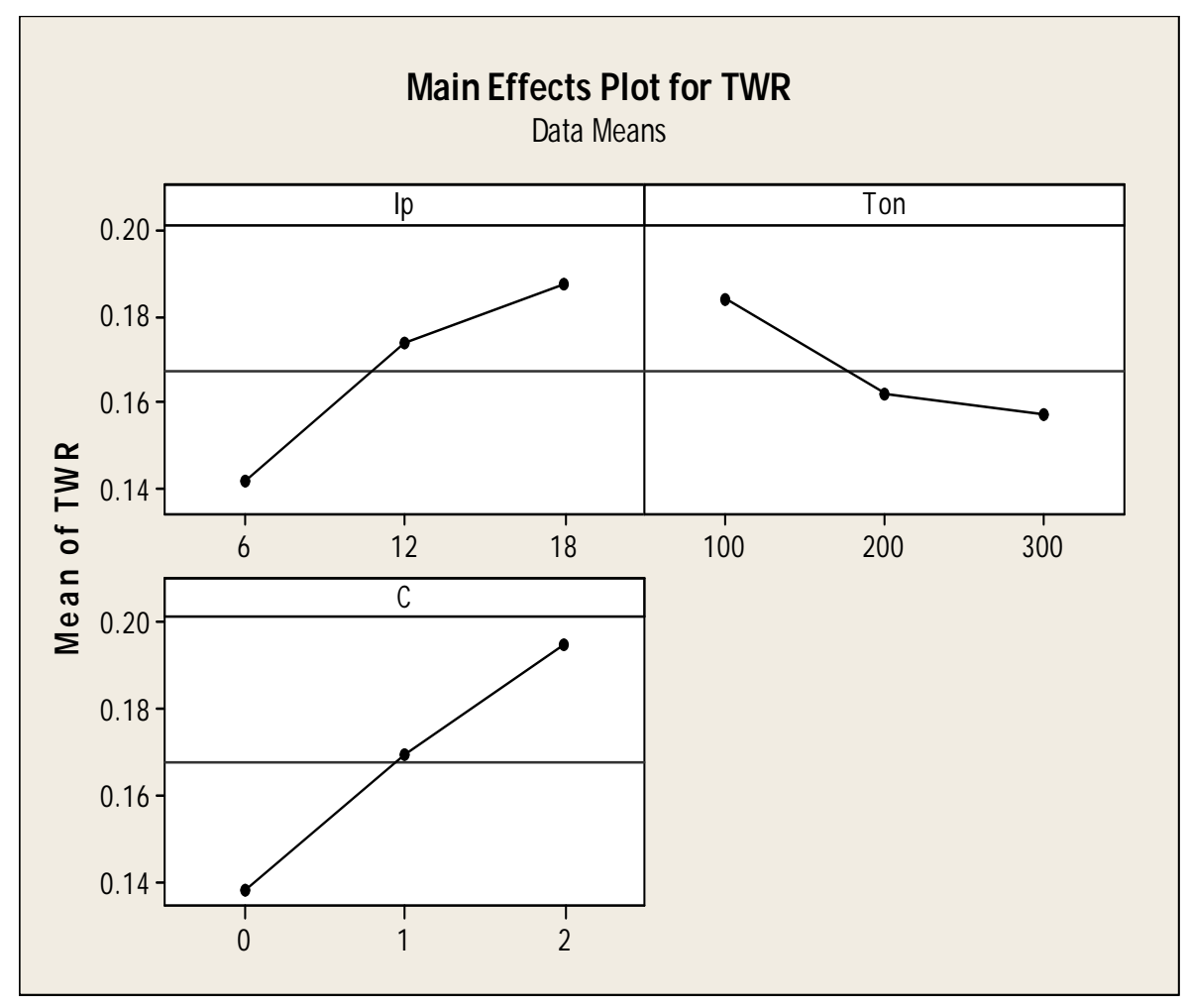

Figure:8 Response Graph for TWR

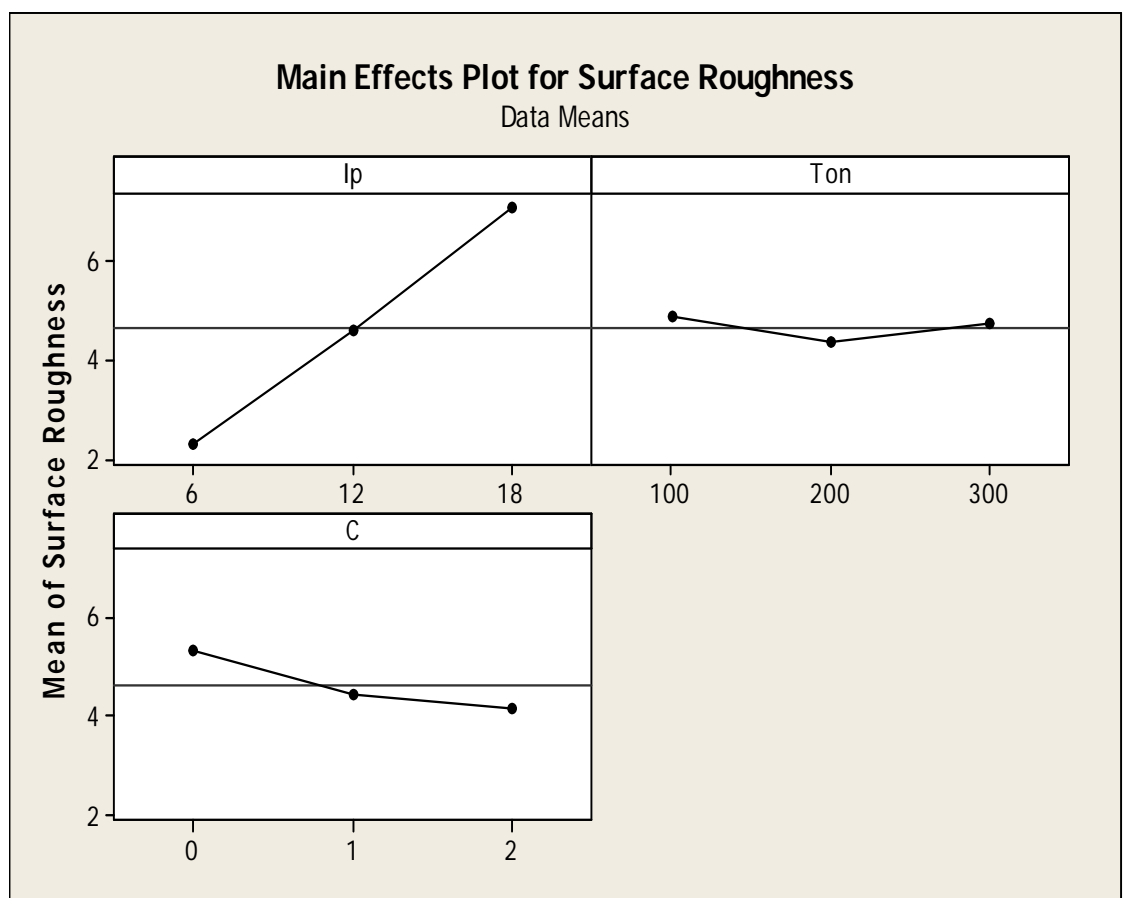

Figure:9 Response Graph for Surface Roughness

The present work on addition of chromium metalpowder in kerosene with changing polarity resulted in high MRR, minimum TWR and Surface Roughness (SR). The results are obtained from the present investigation for selecting the optimum machining conditions for EN-19 work material shown in figure 2, which is extensively used in tool and die industries. Within the range of parameters selected the following specific conclusions are drawn from the experimental results.

1. Maximum MRR is obtained at a high peak current of $18 \mathrm{~A}$, a moderate Ton of $200 \mu \mathrm{s}$, and a low concentration of powder in Normal polarity shown in figure 4.

2. Low TWR is achieved in Normal polarity with low values of peak current of $6 \mathrm{~A}$, minimum values of Ton of $100 \mu \mathrm{s}$, and low concentration of powder as shown in figure 5 . 
3. To get better surface roughness values, a low peak current of $6 \mathrm{~A}$, a moderate Ton of $200 \mu \mathrm{s}$, a low concentration of powder of $1 \mathrm{~g} / \mathrm{L}$, and reverse polarity is preferred.

4. Polarity plays an important role in PMEDM. Higher productivity, i.e. high MRR, is obtained in Normal polarity, whereas better surface quality (surface roughness) is achieved in Reverse polarity. Hence for rough machining Normal polarity can be selected to achieve higher MRR and during finishing a better surface is achieved by changing the polarity i.e. Reverse polarity.

5. The optimal parametric combination for both Normal \& Reverse polarity is shown in table $7 \& 8$.

Table 7: Optimum parametric combination in Normal polarity

\begin{tabular}{|c|c|c|c|c|}
\hline \multirow[b]{2}{*}{ Requirements } & \multirow{2}{*}{$\begin{array}{l}\text { Optimal Combination } \\
\text { ( I / Ton / C ) }\end{array}$} & \multicolumn{3}{|c|}{ Confirmation of results } \\
\hline & & $\begin{array}{c}\text { MRR } \\
(\mathrm{mm3} / \mathrm{min})\end{array}$ & $\begin{array}{c}\text { TWR } \\
\text { (mm3/min) }\end{array}$ & $\operatorname{Ra}(\mu \mathbf{m})$ \\
\hline Higher MRR & $18 \mathrm{~A} / 100 \mu \mathrm{s} / 2 \mathrm{gm} / \mathrm{lit}$ & 12.452 & 0.159 & 11.105 \\
\hline Lower TWR & $6 \mathrm{~A} / 100 \mu \mathrm{s} /$ without powder & 2.500 & 0.056 & 5.845 \\
\hline Lower Ra & $6 \mathrm{~A} / 300 \mu \mathrm{s} / 2 \mathrm{gm} / \mathrm{lit}$ & 2.070 & 0.072 & 4.818 \\
\hline
\end{tabular}

Table 8: Optimum parametric combination in Reverse polarity

\begin{tabular}{|c|c|c|c|c|}
\hline \multirow[b]{2}{*}{ Requirements } & \multirow{2}{*}{$\begin{array}{l}\text { Optimal Combination } \\
\text { ( I / Ton / C ) }\end{array}$} & \multicolumn{3}{|c|}{ Confirmation of results } \\
\hline & & $\begin{array}{c}\text { MRR } \\
(\mathrm{mm} 3 / \mathrm{min})\end{array}$ & $\begin{array}{c}\text { TWR } \\
(\mathrm{mm} 3 / \mathrm{min})\end{array}$ & $\mathbf{R a}(\mu \mathbf{m})$ \\
\hline Higher MRR & $18 \mathrm{~A} / 300 \mu \mathrm{s} / 1 \mathrm{gm} / \mathrm{lit}$ & 0.450 & 0.134 & 6.881 \\
\hline Lower TWR & $6 \mathrm{~A} / 100 \mu \mathrm{s} /$ without powder & 0.186 & 0.084 & 3.155 \\
\hline Lower Ra & $6 \mathrm{~A} / 200 \mu \mathrm{s} / 1 \mathrm{gm} / \mathrm{lit}$ & 0.295 & 0.185 & 1.655 \\
\hline
\end{tabular}

\section{CONCLUSION}

From the experimental results it is observed that, the higher metal removal rate and lower tool wear is achieved with the Normal polarity but better surface finish is achieved with the reverse polarity. It is seen that Normal polarity gives 10-21 times more MRR and 4 times less tool wear rate as compared to reverse polarity in PMEDM. Reverse polarity gives 1.5-2 times better surface finish as compared to Normal polarity, so for the better surface finish reverse polarity is desirable.

\section{ACKNOWLEDGMENT}

I must mention several individuals and organizations that were of enormous help in the development of this work. Professor C. A. Waghmare my supervisor, philosopher and personality with a Midas touch encouraged me to carry this work. His continuous invaluable knowledgably guidance throughout the course of this study helped me to complete the work up to this stage and hope will continue in further research.

I also very thankful to Head of Department Prof. M. V. Kavade for their valuable suggestions, critical examination of work during the progress, I am indebted to them.

In addition, very energetic and competitive atmosphere of the Mechanical Engineering Department had much to do with this work. I acknowledge with thanks to faculty, teaching and non-teaching staff of the department, Central library and Colleagues. 


\section{REFERENCES}

[1] Saurabh Sharma, Anil Kumar, Naveen Beri, Dinesh Kumar, "Effect of Aluminium Powder Addition in dielectric during Electric Discharge Machining of hastelloy on machining performance using reverse polarity" International Journal of Advanced Engineering Technology, IJAET/Vol.I/ Issue III/Oct.-Dec.,2010/13-24.

[2] M. S. Reza, M. A. Azmir, S. H. Tomadi, M. A. Hassan and R. Daud, "Effects of Polarity Parameter on Machining of Tool Steel Workpiece using Electrical Discharge Machining", National Conference in Mechanical Engineering Research and Postgraduate Students (1st NCMER 2010) 26-27 MAY 2010, FKM Conference Hall, UMP, Kuantan, Pahang, Malaysia; pp. 621-626.

[3] Dilshad Ahmad Khan, "Effect of Tool Polarity on the Machining Characteristics in Electric Discharge Machining of silver steel and statistical modelling of the process", International Journal of Engineering Science and Technology (IJEST), Vol. 3 No. 6 June 2011.

[4] B.B. Pradhan and B. Bhattacharyya, "Improvement in microhole machining accuracy by polarity changing technique for microelectrode discharge machining on Ti--6Al--4V", Proceedings of the Institution of Mechanical Engineers, Part B: Journal of Engineering Manufacture 2008 222: 163 DOI: 10.1243/09544054JEM959.

[5] M.M. Rahman, Md. AshikurRahman Khan, K. Kadirgama, M.A. Maleque and Rosli A. Bakar, "Parametric Optimization in EDM of Ti-6Al-4V using Copper Tungsten Electrode and Positive Polarity: A Statistical Approach", Mathematical Methods and Techniques in Engineering and Environmental Science, ISBN: 978-1-61804-046-6.

[6] Sukhpal S. Chatha, Rakesh Bhatia, Hazoor S. Sidhu, Buta S. Sidhu, "Impact of Added Titanium Dioxide in Dielectric of EDM on Surface characteristics and MRR", National Conference on Advancements and Futuristic Trends in Mechanical and Materials Engineering (February 19-20, 2010).

[7] Kuldeep Ojha, R. K. Garg, K. K. Singh, "Experimental Investigation and Modeling of PMEDM Process with Chromium Powder Suspended Dielectric", International Journal of Applied Science and Engineering 2011. 9, 2: 65-81.

[8] Saurabh Sharma, Anil Kumar, Naveen Beri, "study of tool wear rate during powder mixed edm of hastelloy steel.", International Journal of Advanced Engineering Technology, IJAET/Vol.II/ Issue II/April-June, 2011/133-139.

[9] DhananjayPradhan, Dr.S.C.Jayswal "Behaviour OF Copper and Aluminium Electrodes on EDM of EN-8 Alloy Steel", Dhananjay Pradhan et al. / International Journal of Engineering Science and Technology (IJEST), ISSN: 0975-5462 Vol. 3 No. 7 July 2011.

[10] Wei Zhao, "Discussion on the Polarity Effect of EDM", Advanced Materials Research Vols. 154-155 (2011) pp $429-432$.

[11] C Cogun, B O zerkan, and T Karacay "An experimental investigation on the effect of powder mixed dielectric on machining performance in electric discharge machining”, Proc. IMechE Vol. 220 Part B: J. Engineering Manufacture.

[12] Sukhjeet Singh, HarpreetSingh,Jasbir Singh, Rakesh Bhatia, "Effect of Composition of Powder Mixed Dielectric Fluid on Performance of Electric Discharge Machining", National Conference on Advancements and Futuristic Trends in Mechanical and Materials Engineering (Oct. 7-8,2011).

[13] Katsushi Furutani, "Electrical Conditions of Electrical Discharge Machining with Powder Suspended in Working Oil for Titanium Carbide Accretion Process", Department of Advanced Science and Technology, Toyota Technological Institute, ISBN No: 981-048484-4 532. 